Check for updates

Cite this: Chem. Commun., 2020, 56, 14389

Received 5th September 2020,

Accepted 27th October 2020

DOI: $10.1039 / \mathrm{d} 0 \mathrm{cc} 05992 \mathrm{~g}$

rsc.li/chemcomm

\section{Transition metal-free and regioselective vinylation of phosphine oxides and $H$-phosphinates with VBX reagents $\dagger$}

\author{
Laura Castoldi, (ID) $\ddagger^{\mathrm{a}}$ Adam A. Rajkiewicz (D) $\ddagger^{\mathrm{ab}}$ and Berit Olofsson (D) *a
}

\begin{abstract}
A series of phosphine oxides and $\mathrm{H}$-phosphinates were vinylated in the presence of the iodine(III) reagents vinylbenziodoxolones (VBX), providing the corresponding alk-1-enyl phosphine oxides and alk-1-enyl phosphinates in good yields with complete chemoand regioselectivity. The vinylation proceeds in open flask under mild and transition metal-free conditions.
\end{abstract}

Among the plethora of iodine(III) reagents, ${ }^{1}$ benziodoxolone scaffolds have been introduced as more stable alternatives to iodonium salts in alkynylation and trifluoromethylation reactions. ${ }^{2}$ Vinylbenzoiodoxolones (VBX) were recently introduced as efficient vinylating agents. ${ }^{3}$ They have since been used in metal-catalyzed cross couplings and $\mathrm{C}-\mathrm{H}$ vinylations, ${ }^{4}$ as well as in several elegant metal-free reactions. ${ }^{4 c, e, 5}$ We have demonstrated the unique reactivity of VBX in the vinylation of nitrocyclohexane, with regioselective formation of the terminal alkene (Scheme 1a), whereas vinyliodonium salts gave the internal alkene. ${ }^{3}$ To the contrary, the VBX vinylation of thiols and mercaptothiazoles resulted in internal alkene products with high $E$-selectivity (Scheme 1a), ${ }^{6}$ while vinyliodonium salts give the $Z$-isomer through a vinylic $\mathrm{S}_{\mathrm{N}} 2$ mechanism. ${ }^{7}$

The synthesis of VBX reagents is straightforward, and can either be performed in a one-pot reaction from 2-iodobenzoic acid, ${ }^{3}$ or via a preformed iodine(III) species that is reacted with a suitable vinylboronic acid. ${ }^{4 d, g}$ Heteroatom nucleophiles can be added to EBX reagents to further increase the scope of VBX reagents. ${ }^{4 f, g, 8}$

Alkenylphosphorus compounds are primary building blocks in a series of transformations, including reduction, ${ }^{9}$ epoxidation, ${ }^{10}$ Michael addition ${ }^{11}$ and cycloaddition. ${ }^{12}$ Moreover, vinylated

\footnotetext{
${ }^{a}$ Department of Organic Chemistry, Arrhenius Laboratory, Stockholm University, SE-106 91 Stockholm, Sweden. E-mail: berit.olofsson@su.se

${ }^{b}$ Centre of New Technologies, University of Warsaw, Banacha 2C, 02-097, Warsaw, Poland

$\dagger$ Electronic supplementary information (ESI) available: Experimental details, analytical data and NMR spectra of novel compounds. See DOI: 10.1039/ d0cc05992g

\# These authors contributed equally.
}

phosphorus compounds have become of interest for the development of pharmacologically important and biologically active compounds such as antibiotics ${ }^{13}$ and enzyme inhibitors. ${ }^{14}$ Alkenyl phosphine oxides and phosphonates are also valuable monomers in polymer and materials chemistry. ${ }^{15}$

Traditionally, the synthesis of alkenyl phosphorus compounds relies on transition metal-catalyzed cross coupling methodologies; $^{16}$ and terminal alkenes can be prepared through metalcatalyzed hydrophosphorylation of alkynes. ${ }^{17}$ Despite the utility of these methods, common drawbacks include the removal of the transition metal from the final product, the toxicity and the cost of the catalyst, and need for preparation of non-commercial ligands. ${ }^{18}$ Metal-free methodologies for $\mathrm{P}-\mathrm{C}$ bond formation are hence highly desirable. ${ }^{19}$ While several efficient methods for vinylation of phosphine oxides to provide the internal alkene product have recently been reported, ${ }^{20}$ the synthesis of the corresponding terminal alkene product remains difficult. Methods utilizing vinyl sulfones or nitro olefins as vinylation reagent have only been demonstrated with a very limited phosphorus substrate scope (Scheme 1b). ${ }^{21}$

Vinyliodonium salts have been employed in a mild coppercatalyzed procedure with $H$-phosphonates to afford $(E)$ 2-arylvinylphosphonates. $^{22}$ In 2014, the benziodoxolone reagent EBX was demonstrated to be efficient in metal-free alkynylation of

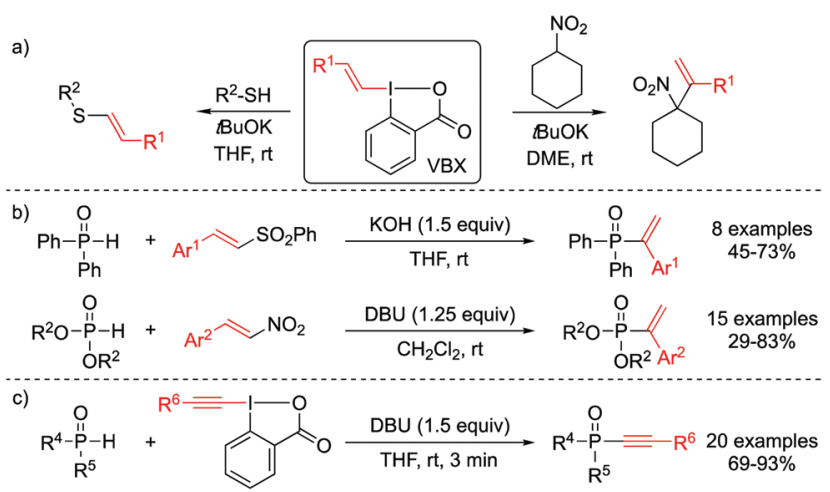

Scheme 1 Transition metal-free vinylations and alkynylations. 
$H$-phosphites, $H$-phosphinates and secondary phosphine oxides under mild conditions and short reaction times (Scheme 1c). ${ }^{23}$ We envisaged that a method involving the novel VBX reagent could be attractive for the construction of C-P bonds. Herein, we report a mild and metal-free, open flask methodology to vinylate phosphine oxides and phosphinates with complete regioselectivity towards the terminal alkene.

Diphenylphosphine oxide (1a) was chosen as the model substrate to study the vinylation of phosphorous compounds with VBX 2a. Surprisingly, the vinylation proceeded with complete regioselectivity in favor of the terminal alkene 3a without formation of any internal alkenes 4 (Table 1). ${ }^{24}$ A series of organic and inorganic bases were screened in THF at room temperature (entries 1-6). The use of DBU and BTMG proved superior to other bases (entries 5 and 6), while no reactivity was detected in the absence of base (entry 4). DBU was selected for further investigations as BTMG is more expensive, and THF was found to be the best solvent (entries 5 and 7-9). Shortening the reaction time to $1 \mathrm{~h}$ and reduced amount of VBX resulted in small drops in yield (entries 10 and 11). Pleasingly, 3a was obtained in $94 \%$ isolated yield by lowering the concentration of the reaction to $0.05 \mathrm{M}$, likely due to increased solubility of VBX (entry 13). We have previously demonstrated that the formed iodobenzoic acid can be recovered and reused for VBX synthesis, thus increasing the sustainability of the process. ${ }^{6}$

With the optimized conditions established, the substrate scope was examined with symmetric and unsymmetric diarylphosphine oxides 1 (Scheme 2a and b). Substrates with electron donating substituents provided high yields of the desired product $(3 \mathbf{a}-\mathbf{g})$, including the sterically congested products $\mathbf{3 d}$ and $\mathbf{3 e}$. A fluorine substituent was also tolerated (3h), whereas electron withdrawing substituents drastically reduced the reactivity. A modest yield of $3 \mathbf{i}$ was obtained under standard conditions, which could be

Table 1 Optimization for phosphine oxides ${ }^{a}$

$\underset{12}{\text { 1a }}$

\begin{tabular}{|c|c|c|c|c|c|}
\hline Entry & Base & Solvent & Conc. $\left[\mathrm{mol} \mathrm{L}^{-1}\right]$ & Time $[\mathrm{h}]$ & Yield $\mathbf{3} \mathbf{a}^{b}[\%]$ \\
\hline 1 & $\mathrm{Et}_{3} \mathrm{~N}$ & THF & 0.1 & 20 & 5 \\
\hline 2 & DMAP & $\mathrm{THF}$ & 0.1 & 20 & $<5$ \\
\hline $3^{c}$ & $\mathrm{Cs}_{2} \mathrm{CO}_{3}$ & THF & 0.1 & 20 & 62 \\
\hline 4 & - & THF & 0.1 & 20 & 0 \\
\hline 5 & DBU & THF & 0.1 & 20 & 88 \\
\hline 6 & BTMG & THF & 0.1 & 20 & 90 \\
\hline 7 & DBU & $\mathrm{Et}_{2} \mathrm{O}$ & 0.1 & 20 & 40 \\
\hline 8 & DBU & Toluene & 0.1 & 20 & 64 \\
\hline 9 & DBU & EtOAc & 0.1 & 20 & 76 \\
\hline 10 & DBU & THF & 0.1 & 1 & 84 \\
\hline $11^{d}$ & DBU & THF & 0.1 & 1 & 80 \\
\hline 12 & DBU & THF & 0.25 & 1 & 78 \\
\hline 13 & DBU & THF & 0.05 & 1 & $93(94)$ \\
\hline
\end{tabular}

${ }^{a}$ Reaction conditions: $1 \mathrm{a}(0.05 \mathrm{mmol})$ and base were stirred in solvent for 5 min before addition of $2 \mathrm{a}$ (1.2 equiv.). ${ }^{b}{ }^{1} \mathrm{H}-\mathrm{NMR}$ yield using trimethoxybenzene as internal standard, isolated yield in brackets. ${ }^{c}$ At $60{ }^{\circ} \mathrm{C}$. $d$ 1.0 equiv. of 2a. DBU = 1,8-diazabicyclo[5.4.0] undec-7-ene; BTMG = 2-tertbutyl-1,1,3,3-tetramethylguanidine; DMAP = 4-(dimethylamino)pyridine.

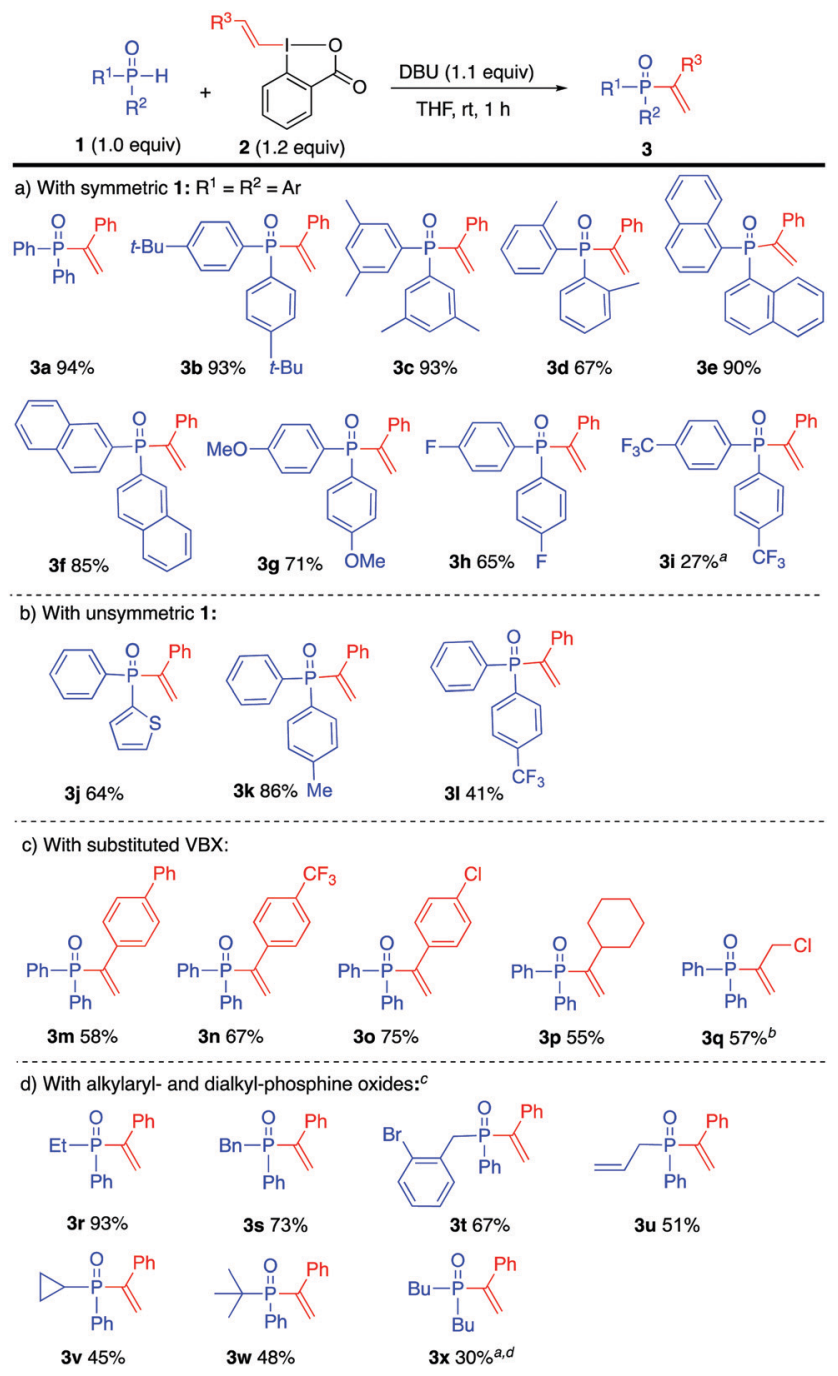

Scheme 2 Scope with diaryl- and alkylaryl-phosphine oxides. ${ }^{a}$ At $60{ }^{\circ} \mathrm{C}$, 20 h. ${ }^{b}$ At $-10{ }^{\circ} \mathrm{C}, 2$ h. ${ }^{c}$ At $60{ }^{\circ} \mathrm{C}, 2$ h. ${ }^{d}$ NMR yield.

improved to $27 \%$ yield by increasing the temperature and prolonging the reaction time.

Unsymmetric phosphine oxides were prepared from alkyl phenyl- $H$-phosphinates by reaction with the corresponding Grignard/organolithium reagent, ${ }^{24,25}$ and subsequently examined in the vinylation. The unsymmetric product $3 \mathbf{j}$, bearing a thiophene moiety, and phenyl( $p$-tolyl)phosphine oxide (3k) were obtained in good to high yields. The presence of a $\mathrm{CF}_{3}$ group in product 31 decreased the yield to $41 \%$.

The scope of VBX reagents was investigated by vinylation of diphenylphosphine oxide (1a, Scheme 2c). VBX reagents with both electron-donating and -withdrawing substituents on the styryl moiety were well tolerated and gave the desired alk-1-enyl phosphine oxides $\mathbf{3 m - \mathbf { m }}$ in good yields. Aliphatic VBX reagents have previously proved problematic and provided complex product mixtures. ${ }^{3,6}$ Pleasingly, aliphatic VBX reagents could be employed in the P-vinylation to provide the cyclohexyl product 3p. Also the 3chloropropenyl product 3q, with a sensitive functional group, was successfully synthesized upon lowering the temperature. However, the Z-configured sulfonamide-substituted VBX reported 


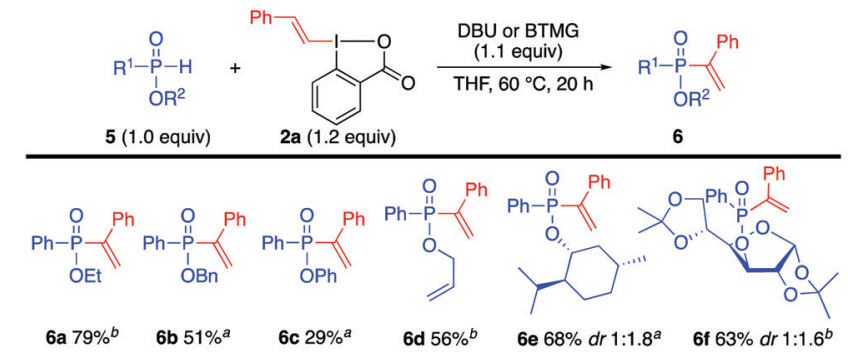

Scheme 3 Scope with $H$-phosphinates. ${ }^{a}$ DBU used as a base. ${ }^{b}$ BTMG used as a base.

by Waser $^{4 c}$ and our core-dimethylated $Z$-VBX derivative ${ }^{6}$ did not afford the desired product. Trisubstituted VBXs also proved unreactive. $^{24}$

Alkylarylphosphine oxides proved to be less reactive towards VBX, and required additional optimization. Ethyl-phenylphosphine oxide could be vinylated to give $3 \mathbf{r}$ in excellent yield within 2 hours at $60{ }^{\circ} \mathrm{C}$ (Scheme 2d). Other alkyl- and allyl derivatives were vinylated in the same manner to afford products $3 \mathbf{s}-\mathbf{v}$. The successful synthesis of tert-butyl product $3 \mathbf{w}$ illustrates the high tolerance for sterical hindrance. Dialkyl-phosphine oxides were, on the other hand very unreactive, and product $3 \mathbf{x}$ could only be obtained in modest yield upon prolonged reaction time at $60{ }^{\circ} \mathrm{C}$.

We have recently investigated the effect of several coresubstituted VBX reagents in the vinylation of thiols, ${ }^{6}$ and substituent effects have previously been demonstrated with EBX reagents ${ }^{26}$ and other iodine(III) compounds. ${ }^{27}$ We hence investigated the influence of core-substituted VBX reagents in P-vinylation of $H$-phosphinates, as they proved less reactive than phosphine oxides. Phosphinate 5a was reacted with a series of core-substituted VBX reagents to investigate electronic and steric effects (see ESI $\dagger$ ). $\mathrm{Me}_{2}$-VBX, which we previously reported to improve the $S$-vinylation yields, ${ }^{6}$ showed comparable reactivity to the unsubstituted VBX, whereas other changes in the core structure reduced the yield of $\mathbf{6 a}$. A control reaction with the corresponding acyclic vinyliodonium salt gave only $10 \%$ yield of 6 a.

The desired alkenylation of $H$-phosphinates proved viable at $60{ }^{\circ} \mathrm{C}$ for $20 \mathrm{~h}$ using either DBU or BTMG, ${ }^{24}$ and the scope was examined with both bases as the outcome was substrate dependent (Scheme 3). ${ }^{24}$ Ethyl phenylphosphinate and benzyl phenylphosphinate gave $\mathbf{6 a}$ and $\mathbf{6 b}$, respectively. Phenoxy and allyloxy products $\mathbf{6 c}$ and $\mathbf{6 d}$ could also be obtained in this fashion (the isolated yield of $\mathbf{6 c}$ is affected by the instability of this compound). More complex substrates were also suitable for this methodology, as exemplified by the vinylation of $(R)$-phenyl menthoxy phosphinate $5 \mathbf{e}$ and glucose diacetonide-derived $\mathrm{H}$-phosphonate $\mathbf{5} \mathbf{f}$ to give products $6 \mathbf{e}$ and $\mathbf{6 f}$ in good yields as a mixture of diastereoisomers. The vinylation of $H$-phosphonates proved to be sluggish, despite optimization attempts under various conditions. ${ }^{24}$

The different regiochemistry obtained in vinylations of phosphorus and sulfur nucleophiles with VBX is intriguing, and preliminary tests with radical scavengers were conducted to investigate whether a radical pathway could be operating. The reaction of diphenylphosphine oxide (1a) with TEMPO under standard conditions afforded $82 \%$ yield of $3 \mathrm{a}$, which is comparable with the results without additive, indicating that a radical pathway is unlikely. ${ }^{24}$ The observed regiochemistry would be consistent with a phospha-Michael-type addition ${ }^{28}$ followed by proton shift and elimination, but alternative pathways cannot be excluded at this point.

To conclude, the recently discovered reagent VBX was employed to efficiently vinylate a wide range of phosphine oxides and $H$-phosphinates. The reactions were performed in open flask under mild and transition metal free conditions, and delicate functional groups were tolerated. Both aromatic and aliphatic vinyl moieties could be transferred, and the electronic and steric influences of core-substituted VBX derivatives were investigated. We are currently performing an extensive mechanistic investigation on the reactivity of VBX with several nucleophiles under metal-free conditions, and will report the results in due time.

We thank Ester Maria Di Tommaso for analytical support. We acknowledge Carl Trygger Foundation (CTS 17:341, Fellowship for LC), the National Science Centre Poland (2016/22/E/ ST5/00566) and The Warsaw University's Integrated Development Programme (both Fellowships for AAR), and the Swedish Research Council (2015-04404, 2019-04232) for financial support.

\section{Conflicts of interest}

There are no conflicts to declare.

\section{Notes and references}

1 (a) V. V. Zhdankin, Hypervalent Iodine Chemistry, Wiley, Chichester, UK, 2014; (b) Hypervalent Iodine Chemistry, ed. T. Wirth, Springer International Publishing, Cham, 2016; (c) The Chemistry of Hypervalent Halogen Compounds, ed. B. Olofsson, I. Marek and Z. Rappoport, Wiley, 2019.

2 (a) J. Charpentier, N. Früh and A. Togni, Chem. Rev., 2015, 115, 650-682; (b) Y. Li, D. P. Hari, M. V. Vita and J. Waser, Angew. Chem., Int. Ed., 2016, 55, 4436-4454; (c) D. P. Hari, P. Caramenti and J. Waser, Acc. Chem. Res., 2018, 51, 3212-3225.

3 E. Stridfeldt, A. Seemann, M. J. Bouma, C. Dey, A. Ertan and B. Olofsson, Chem. - Eur. J., 2016, 22, 16066-16070.

4 (a) J. Wu, X. Deng, H. Hirao and N. Yoshikai, J. Am. Chem. Soc., 2016, 138, 9105-9108; (b) J. Wu, K. Xu, H. Hirao and N. Yoshikai, Chem. Eur. J., 2017, 23, 1521-1525; (c) P. Caramenti, N. Declas, R. Tessier, M. D. Wodrich and J. Waser, Chem. Sci., 2019, 10, 3223-3230; (d) A. Boelke, L. D. Caspers and B. J. Nachtsheim, Org. Lett., 2017, 19, 5344-5347; (e) B. Liu, C.-H. Lim and G. M. Miyake, J. Am. Chem. Soc., 2018, 140, 12829-12835; $(f)$ R. Tessier, J. Ceballos, N. Guidotti, R. Simonet-Davin, B. Fierz and J. Waser, Chem, 2019, 5, 2243-2263; (g) G. Pisella, A. Gagnebin and J. Waser, Org. Lett., 2020, 22, 3884-3889.

5 (a) J. Davies, N. S. Sheikh and D. Leonori, Angew. Chem., Int. Ed., 2017, 56, 13361-13365; (b) S. G. E. Amos, S. Nicolai, A. Gagnebin, F. L. Vaillant and J. Waser, J. Org. Chem., 2019, 84, 3687-3701; (c) B. Liu, J. Alegre-Requena, R. Paton and G. Miyake, Chem. - Eur. J., 2020, 26, 2386-2394; (d) N. Declas and J. Waser, Angew. Chem., Int. Ed., 2020, 59, 18256-18260.

6 L. Castoldi, E. M. Di Tommaso, M. Reitti, B. Gräfen and B. Olofsson, Angew. Chem., Int. Ed., 2020, 59, 15512-15516.

7 (a) M. Ochiai, S. Yamamoto, T. Suefuji and D.-W. Chen, Org. Lett., 2001, 3, 2753-2756; For recent developments with vinyliodonium and vinylchloronium salts, see: $(b)$ Á. Mészáros, A. Székely, A. Stirling and Z. Novák, Angew. Chem., Int. Ed., 2018, 57, 
6643-6647; (c) Y. Watanabe, T. Takagi, K. Miyamoto, J. Kanazawa and M. Uchiyama, Org. Lett., 2020, 22, 3469-3473.

8 (a) B. Wu, J. Wu and N. Yoshikai, Chem. - Asian J., 2017, 12, 3123-3127; (b) D. Shimbo, A. Shibata, M. Yudasaka, T. Maruyama, N. Tada, B. Uno and A. Itoh, Org. Lett., 2019, 21, 9769-9773; (c) J. Wu, X. Deng and N. Yoshikai, Chem. - Eur. J., 2019, 25, 7839-7842; (d) P. Caramenti, N. Declas, R. Tessier, M. D. Wodrich and J. Waser, Chem. Sci., 2019, 10, 3223-3230.

9 (a) P. Cheruku, A. Paptchikhine, T. L. Church and P. G. Andersson, J. Am. Chem. Soc., 2009, 131, 8285-8289; (b) K. Dong, Z. Wang and K. Ding, J. Am. Chem. Soc., 2012, 134, 12474-12477; (c) D.-Y. Wang, X.-P. Hu, J. Deng, S.-B. Yu, Z.-C. Duan and Z. Zheng, J. Org. Chem., 2009, 74, 4408-4410.

10 Y. Ono and L.-B. Han, Tetrahedron Lett., 2006, 47, 421-424.

11 S. Sulzer-Mossé, M. Tissot and A. Alexakis, Org. Lett., 2007, 9, 3749-3752.

12 N. Rabasso and A. Fadel, Tetrahedron Lett., 2010, 51, 60-63.

13 C. Giordano and G. Castaldi, J. Org. Chem., 1989, 54, 1470-1473.

14 (a) J.-J. Shie, J.-M. Fang, S.-Y. Wang, K.-C. Tsai, Y.-S. E. Cheng, A.-S. Yang, S.-C. Hsiao, C.-Y. Su and C.-H. Wong, J. Am. Chem. Soc., 2007, 129, 11892-11893; (b) X. Lu, C. Sun, W. J. Valentine, S. E, J. Liu, G. Tigyi and R. Bittman, J. Org. Chem., 2009, 74, 3192-3195; (c) Z. Liu, N. MacRitchie, S. Pyne, N. J. Pyne and R. Bittman, Bioorg. Med. Chem., 2013, 21, 2503-2510.

15 (a) M. Schmider, E. Müh, J. E. Klee and R. Mülhaupt, Macromolecules, 2005, 38, 9548-9555; (b) J. Parvole and P. Jannasch, Macromolecules, 2008, 41, 3893-3903; (c) T. Sato, M. Hasegawa, M. Seno and T. Hirano, J. Appl. Polym. Sci., 2008, 109, 3746-3752; (d) S. V. Levchik and E. D. Weil, Polym. Int., 2005, 54, 11-35.

16 (a) L. Liu, Y. Wang, Z. Zeng, P. Xu, Y. Gao, Y. Yin and Y. Zhao, Adv. Synth. Catal., 2013, 355, 659-666; (b) Y. Wu, L. Liu, K. Yan, P. Xu, Y. Gao and Y. Zhao, J. Org. Chem., 2014, 79, 8118-8127; (c) J. Hu, N. Zhao, B. Yang, G. Wang, L.-N. Guo, Y.-M. Liang and S.-D. Yang, Chem. - Eur. J., 2011, 17, 5516-5521; (d) G. Hu, Y. Gao and Y. Zhao, Org. Lett., 2014, 16, 4464-4467; (e) M. Niu, H. Fu, Y. Jiang and Y. Zhao, Chem. Commun., 2007, 272-274; $(f)$ G. Evano, K. Tadiparthi and F. Couty, Chem. Commun., 2011, 47, 179-181.
17 (a) L.-B. Han and M. Tanaka, J. Am. Chem. Soc., 1996, 118, 1571-1572; (b) Q. Xu, R. Shen, Y. Ono, R. Nagahata, S. Shimada, M. Goto and L.-B. Han, Chem. Commun., 2011, 47, 2333-2335; (c) N. Dobashi, K. Fuse, T. Hoshino, J. Kanada, T. Kashiwabara, C. Kobata, S. K. Nune and M. Tanaka, Tetrahedron Lett., 2007, 48, 4669-4673; (d) L.-B. Han, C. Zhang, H. Yazawa and S. Shimada, J. Am. Chem. Soc., 2004, 126, 5080-5081; (e) H. Li-Biao, O. Yutaka, X. Qing and S. Shigeru, Bull. Chem. Soc. Jpn., 2010, 83, 1086-1099.

18 C.-L. Sun and Z.-J. Shi, Chem. Rev., 2014, 114, 9219-9280.

19 Recent metal-free examples for P-C bond formation: (a) B. Yang, S.-M. Hou, S.-Y. Ding, X.-N. Zhao, Y. Gao, X. Wang and S.-D. Yang, Adv. Synth. Catal., 2018, 360, 4470-4474; (b) Q. Fu, Z.-Y. Bo, J.-H. Ye, T. Ju, H. Huang, L.-L. Liao and D.-G. Yu, Nat. Commun., 2019, 10, 3592.

20 (a) L. Liu, D. Zhou, J. Dong, Y. Zhou, S.-F. Yin and L.-B. Han, J. Org. Chem., 2018, 83, 4190-4196; (b) J. Shen, R.-X. Yu, Y. Luo, L.-X. Zhu, Y. Zhang, X. Wang, B. Xiao, J.-B. Cheng, B. Yang and G.-Z. Li, Eur. J. Org. Chem., 2019, 2065-2070; (c) H. Wang, Y. Li, Z. Tang, S. Wang, H. Zhang, H. Cong and A. Lei, ACS Catal., 2018, 8, 10599-10605.

21 (a) H.-M. Guo, Q.-Q. Zhou, X. Jiang, D.-Q. Shi and W.-J. Xiao, Adv. Synth. Catal., 2017, 359, 4141-4146; (b) N. Ono, N. Banshou, S. Ito, T. Murashima and T. Ogawa, J. Heterocycl. Chem., 1997, 34, 1243-1246; (c) H.-X. Chen, L.-J. Huang, J.-B. Liu, J. Weng and G. Lu, Phosphorus, Sulfur Silicon Relat. Elem., 2014, 189, 1858-1866. 22 S. Thielges, P. Bisseret and J. Eustache, Org. Lett., 2005, 7, 681-684. 23 C. C. Chen and J. Waser, Chem. Commun., 2014, 50, 12923-12926. 24 See the ESI, $\dagger$ for details.

25 A. Tripolszky and G. Keglevich, Lett. Org. Chem., 2018, 15, 387-393. 26 (a) D. Fernández González, J. P. Brand, R. Mondière and J. Waser, Adv. Synth. Catal., 2013, 355, 1631-1639; (b) A. H. Abazid and B. J. Nachtsheim, Angew. Chem., Int. Ed., 2020, 59, 1479-1484.

27 (a) A.-A. Guilbault and C. Y. Legault, ACS Catal., 2012, 2, 219-222; (b) J. Malmgren, S. Santoro, N. Jalalian, F. Himo and B. Olofsson, Chem. - Eur. J., 2013, 19, 10334-10342.

28 D. Enders, A. Saint-Dizier, M.-I. Lannou and A. Lenzen, Eur. J. Org. Chem., 2006, 29-49. 